\title{
PTEN targeting: the search for novel insulin sensitisers provides new insight into obesity research
}

\author{
Francesco Beguinot
}

Published online: 29 November 2006

(C) Springer-Verlag 2006

\author{
Abbreviations \\ PI3K phosphatidylinositol 3-kinase \\ $\mathrm{PIP}_{3}$ phosphatidylinositol 3,4,5-trisphosphate \\ PTEN phosphatase and tensin homologue \\ SH2 SRC homology domain 2 \\ SHIP SH2-containing inositol 5-phosphatase
}

Breakthrough information in one field of science is often generated by studies in other areas. This has been the case for the phosphatase and tensin homologue (PTEN) and its identification as a drug discovery target for type 2 diabetes. In 1996, the susceptibility gene for Cowden syndrome (now known as PTEN) was mapped to human chromosome $10 \mathrm{q} 22-\mathrm{q} 23$ [1]. Cowden syndrome is an autosomal dominant disorder characterised by multiple hamartomas, which affect derivatives of all three germ layers, and increased risks of breast, thyroid and endometrial cancers [2]. Germline mutations in the tumour-suppressor gene PTEN have been found in $80 \%$ of patients affected by Cowden syndrome [3]. PTEN encodes a dual-function lipid and protein phosphatase that represents a major 3-phosphatase in the phosphatidylinositol 3-kinase (PI3K)/Akt signalling system $[4,5]$. PTEN also represents the first phosphatase gene to be implicated in the aetiology of an inherited cancer syndrome. A number of disorders associ-

F. Beguinot $(\square)$

Department of Cellular and Molecular Biology and Pathology,

University of Naples 'Federico II',

5 via Sergio Pansini,

Naples 80131, Italy

e-mail: beguino@unina.it

\section{F. Beguinot}

C.N.R. Institute of Experimental Endocrinology and Oncology,

University of Naples 'Federico II',

5 via Sergio Pansini,

Naples 80131, Italy ated with germline PTEN mutations have been subsequently recognised.

Following insulin exposure, the PI3K-dependent increase in levels of phosphatidylinositol 3,4,5-trisphosphate $\left(\mathrm{PIP}_{3}\right)$ results in the membrane localisation and/or activation of a number proteins that possess a pleckstrin homology $(\mathrm{PH})$ domain [6]. One such protein is the serine/threonine kinase known as phosphoinositide-dependent kinase 1, which phosphorylates and activates several downstream kinases, including AKT1-3 [7] (Fig. 1). In addition, the protein kinase mammalian target of rapamycin (mTOR), which forms a complex with the regulatory protein rictor, has recently been identified as phosphoinositide-dependent kinase 2, which also phosphorylates AKT [8]. These $\mathrm{PIP}_{3}$-dependent events induce important metabolic responses, including glucose transport, lipid and glycogen synthesis, modulation of gene expression, cell proliferation and inhibition of apoptosis. The PI3K pathway mediates the effects of insulin [9] and leptin [10] on satiety. As these mechanisms are relevant to cell metabolism, it was postulated that $\mathrm{PIP}_{3}$ breakdown may also affect the physiology of insulin action, leading to greater focus on the function of PTEN in insulin signalling. Indeed, a number of studies found that, in addition to its tumoursuppressor function, PTEN serves as a major regulator of PI3K signalling in a number of cells. Much of this work was prompted by the finding that DAF18, the Caenorhabditis elegans PTEN homologue, downregulates insulin receptor-like signalling in the worm [11]. Insulin signalling 


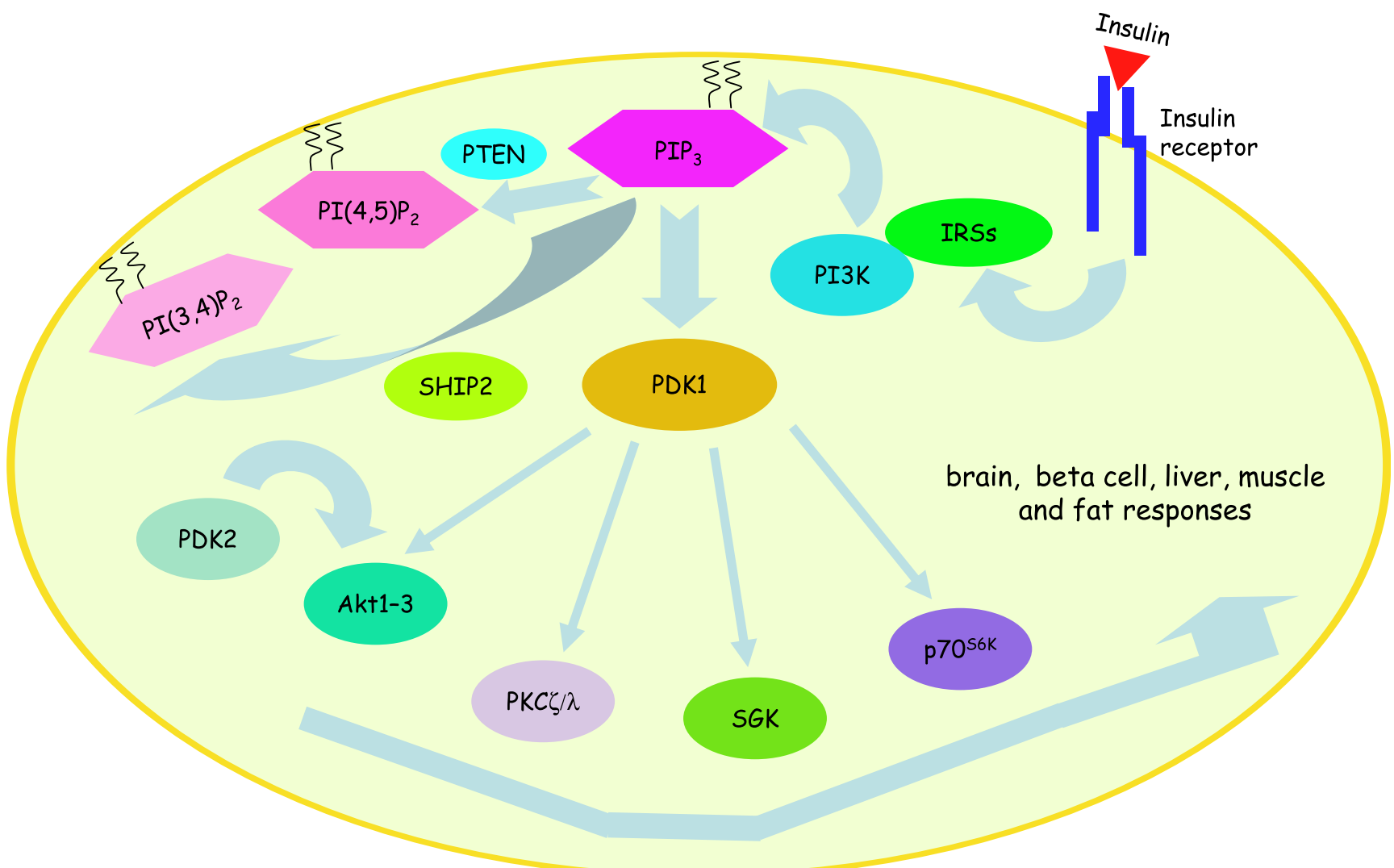

Fig. 1 Molecular events following insulin activation of PI3K. Insulininduced IRS-PI3K association activates PI3K, causing phosphorylation of phosphatidylinositol 4,5-bisphosphate $\left[\mathrm{PI}(4,5) \mathrm{P}_{2}\right]$, increased levels of $\mathrm{PIP}_{3}$, and recruitment/activation of PI3K-dependent molecules, including the serine/threonine kinase phosphatidylinositol-

is also negatively regulated by PTEN in Drosophila melanogaster [12].

Studies on mice with PTEN ablation in liver [13, 14], adipose [15] or skeletal muscle tissues [16] have investigated the effect of PTEN on whole-body glucose homeostasis. In general, this work has provided further support for a role for PTEN in insulin sensitivity and metabolic regulation (Table 1). Fasting plasma glucose and insulin levels were reduced, and glucose tolerance was enhanced, in mice with liver-specific PTEN ablation. However, these mice exhibited a marked hepatomegaly and liver steatosis, suggesting fat redistribution from other tissues to liver. In addition, all the PTEN knock-out mice developed liver tumours by 18 months of age. While excess tumour occurrence was not evident in mice heterozygous for the PTEN gene, these mice showed no improved insulin sensitivity, suggesting that partial inhibition of liver PTEN activity may not represent an effective approach to insulin resistance in type 2 diabetes. Fat-specific PTEN ablation also lowered fasting plasma insulin and improved glucose tolerance in mice, with a significant improvement in whole-body sensitivity to insulin. In contrast, skeletal muscle-specific PTEN knock-out mice exhibited little metabolic abnormality. However, when subjected to a high- dependent kinase 1 (PDK1). PDK-1 is a major regulator of a number of downstream effectors eliciting the wide spectrum of insulin biological responses in sensitive tissues. The 3-phosphatase PTEN and the 5-phosphatase SHIP2 attenuate these effects by dephosphorylating $\mathrm{PIP}_{3}$. SGK: serum/glucocorticoid regulated kinase

fat diet, these animals showed protection against the development of hyperglycaemia and abnormalities in glucose tolerance. Cell proliferation in fat and muscle was not

Table 1 Effect of PTEN perturbation on glucose homeostasis in the mouse

\begin{tabular}{|c|c|c|}
\hline Genetic perturbation & Metabolic phenotype & Reference \\
\hline Liver-specific ablation & $\begin{array}{l}\text { Reduced fasting plasma } \\
\text { insulin, enhanced glucose } \\
\text { tolerance and insulin } \\
\text { sensitivity }\end{array}$ & {$[13,14]$} \\
\hline Fat-specific ablation & $\begin{array}{l}\text { Reduced fasting plasma } \\
\text { insulin, enhanced glucose } \\
\text { tolerance and insulin } \\
\text { sensitivity }\end{array}$ & [15] \\
\hline Muscle-specific ablation & $\begin{array}{l}\text { Protection from insulin- } \\
\text { resistance and diabetes } \\
\text { when exposed to high-fat } \\
\text { diet }\end{array}$ & [16] \\
\hline $\begin{array}{l}\text { Ubiquitous } \\
\text { haploinsufficiency }\end{array}$ & $\begin{array}{l}\text { Fasting hypoglycaemia, } \\
\text { enhanced glucose } \\
\text { tolerance and insulin } \\
\text { sensitivity }\end{array}$ & [17] \\
\hline
\end{tabular}


affected by loss of PTEN, supporting the possibility that targeted inhibition of PTEN function in these tissues may improve insulin sensitivity in a safe and effective manner.

In contrast with these studies, the work by Wong et al. in this issue of Diabetologia has defined the effect of a partial systemic reduction of PTEN on the regulation of insulin sensitivity in intact mice [17]. These studies were conducted in PTEN haploinsufficient animals with only a $15-50 \%$ reduction in tissue levels of PTEN. The haploinsufficiency did however greatly increase insulin sensitivity, thus demonstrating that small systemic changes in the levels of PTEN may improve insulin action. Based on previous studies in the tissue-specific PTEN knock-out mice, this is an unexpected finding, as mice heterozygous for the PTEN gene in liver do not show improved insulin sensitivity. The pro-apoptotic effect of PTEN does raise concerns regarding the safety of PTEN targeting as a means of improving insulin action in chronic disorders such as type 2 diabetes. Even so, studies on PTEN biology have provided proof-of-concept evidence for the potential of inhibiting $\operatorname{PtdIns}(3,4,5) \mathrm{P}_{3}$ phosphatases for enhancing insulin sensitivity in insulin-resistant states.

These advances have opened new and exciting avenues of investigation into the regulation of food intake and peripheral energy metabolism, and have increased interest regarding another family of lipid phosphatases, the SRC homology domain 2 (SH2)-containing inositol 5-phosphatases (SHIPs). Of these, SHIP2 (encoded by the gene Inppl1) is highly expressed in skeletal muscle and brain [18]. Unlike PTEN, which acts on both PtdIns $(3,4) \mathrm{P}_{2}$ and $\mathrm{PIP}_{3}$, SHIP2 catalyses only $\mathrm{PIP}_{3}$ hydrolysis. Wong et al. [17] point out that SHIP2 may not have a physiological role in regulating glucose homeostasis, consistent with the concept that PTEN and not SHIP2 is the major phosphatase involved in desensitising insulin signalling along the PI3K/ Akt pathway. Unexpectedly, mice engineered to be null for Inppl1 were resistant to obesity induced by a high-fat diet [18]. Indeed, Inppl1 knock-out mice respond to a high-fat diet by increasing energy expenditure and preferentially eliminating the excess fat mass. Given the high level of Inppl1 expression in brain, it has been proposed that central mechanisms regulating food intake and energy metabolism, including insulin signalling, might be affected by reduced lipid 5'-phosphatase activity. Thus, compared with PTEN, SHIP2 exhibits greater potential as a drug target in obesity and diabetes. In vitro and in vivo investigations indicate possible efficacy in these disorders and, in contrast to PTEN knock-out mice, Inppl1-null mice feature no increase in tumour occurrence after more than a year of survival. The exciting perspectives offered by SHIP2 targeting are tempered by difficulties in predicting the consequences of in vivo exposure to inhibitors of SHIP2 catalytic activity, and in identifying inhibitors of potential pharmacological interest.
As noted by Sherlock Holmes, Sir Arthur Conan Doyle's famous detective, when one follows two separate chains of thought, points of intersection eventually emerge which should approximate the truth. Studies on an inherited cancer syndrome and the pathogenesis of type 2 diabetes seem to follow this maxim. Interestingly, in this case, approximation to the truth seems to point towards a third disorder: obesity.

\section{References}

1. Nelen MR, Padberg GW, Peeters EAJ et al (1996) Localization of the gene for Cowden disease to 10q22-23. Nat Genet 13:114-116

2. Eng C (2000) Will the real Cowden syndrome please stand up: revised diagnostic criteria. J Med Genet 37:828-830

3. Liaw D, Marsh DJ, Li J et al (1997) Germline mutations of the PTEN gene in Cowden disease, an inherited breast and thyroid cancer syndrome. Nat Genet 16:64-67

4. Li D-M, Sun H (1997) TEP1, encoded by a candidate tumor suppressor locus, is a novel protein tyrosine phosphatase regulated by transforming growth factor B. Cancer Res 57:2124-2129

5. Maehama T, Dixon JE (1998) The tumor suppressor PTEN/ MMAC1 dephosphorylates the lipid second messenger phosphoinositol 3,4,5-triphosphate. J Biol Chem 273:13375-13378

6. Vanhaesebroeck B, Alessi DR (2000) The PI3K-PDK1 connection: more than just a road to PKB. Biochem J 346:561-576

7. Mora A, Komander D, van Aaalten DM, Alessi DR (2004) PDK1, the master regulator of AGC kinase signal transduction. Semin Cell Dev Biol 15:161-170

8. Sarbassov DD, Guertin DA, Ali SM, Sabatini DM (2005) Phosphorylation and regulation of Akt/PKB by the rictor-mTOR complex. Science 307:1098-1101

9. Carvalheira JB, Ribeiro EB, Araujo EP et al (2003) Selective impairment of insulin signalling in the hypothalamus of obese Zucker rats. Diabetologia 46:1629-1640

10. Zhao AZ, Huan JN, Gupta S, Pal R, Sahu A (2002) A phosphatidylinositol 3-kinase phosphodiesterase 3B-cyclic AMP pathway in hypothalamic action of leptin on feeding. Nat Neurosci 5:727-728

11. Ogg S, Ruvkun G (1998) The C. elegans PTEN homolog DAF-18 acts in the insulin receptor-like metabolic signalling pathway. Mol Cell 2:887-893

12. Goberdhan DC, Paricio N, Goodman EC, Mlodzick M, Wilson C (1999) Drosophila tumor suppressor PTEN controls cell size and number by antagonizing the Chico/PI3-kinase signalling pathway. Genes Dev 13:3244-3258

13. Horie Y, Suzuki A, Kataoka E et al (2004) Hepatocyte-specific PTEN deficiency results in steatohepatitis and hepatocellular carcinomas. J Clin Invest 113:1774-2087

14. Stiles B, Wang Y, Stahl A et al (2004) Liver-specific deletion of negative regulator PTEN results in fatty liver and insulin hypersensitivity. Proc Natl Acad Sci USA 101:2082-2087

15. Kurlawalla-Martinez C, Stiles B, Wang Y et al (2005) Insulin hypersensitivity and resistance to streptozotocin-induced diabetes in mice lacking PTEN in adipose tissue. Mol Cell Biol 25:2498 2510

16. Wijesekara N, Konrad D, Eweida M et al (2005) Muscle-specific PTEN deletion protects against insulin resistance and diabetes. Mol Cell Biol 25:1135-1145

17. Wong JT, Kim PTW, Peacock JW (2006) PTEN (phosphatase and tensin homologue gene) haploinsufficiency promotes insulin hypersensitivity. Diabetologia DOI 10.1007/s00125-006-0531-x

18. Sleeman MW, Wortley KM, Lai KM et al (2005) Absence of the lipid phosphatase SHIP2 confers resistance to dietary obesity. Nat Med 11:199-205 